\title{
A comparative study of the integer wavelet transform applied to seismic data lossless compression
}

Julio Nobre Lopes ${ }^{* 1}$, Paula Frederick', Paulo Ivson'1, Renata Nascimento ${ }^{1},{ }^{1}$ Tecgraf Institute/PUC-Rio

Copyright 2021, SBGf - Sociedade Brasileira de Geofísica

This paper was prepared for presentation during the $17^{\text {th }}$ International Congress of the Brazilian Geophysical Society held in Rio de Janeiro, Brazil, 16-19 August 2021.

Contents of this paper were reviewed by the Technical Committee of the $17^{\text {th }}$ International Congress of the Brazilian Geophysical Society and do not necessarily represent any position of the SBGf, its officers or members. Electronic reproduction or storage of any part of this paper for commercial purposes without the written consent of the Brazilian Geophysical Society is prohibited.

\section{Abstract}

The use of massive amounts of seismic data is becoming more frequent and required in seismic processing and analysis. In this context, data compression becomes an essential strategy to minimize the resources to store and transmit these datasets.

Wavelet transforms are commonly used at the decorrelation stage of compression schemes, as presented in Stigant et al. (1995) and Khkne et al. (2000). For lossless compression of integer samples, the integer wavelet transform (IWT) is a suitable approach as described in Giurcaneanu et al. (1999) and Wang et al (2004). In this work, a study was performed on seismic data compression evaluating the improvement of the compression ratio when the same encoding strategy is applied on integer wavelet coefficients instead of the original samples.

\section{Results}

In order to evaluate the gains in compression ratio (CR) by compressing integer wavelet coefficients, three different seismic volumes of data were selected. For each set of data, several libraries and codecs (e.g. C-Blosc2, TurboPFor, FastPFor, LZ4, zstd, and SIMDComp) processed original samples and wavelet coefficients to verify if results were consistent through different compression schemes.

For each seismic volume, it was analyzed how often the compression of integer wavelet coefficients produced a higher CR than that of the original samples. It was also verified what the best $C R$ was in each case.

The table below shows the percentage of libraries that obtained better CRs for the original samples, and for the coefficients. In the case of the F3Block volume, for example, $14.29 \%$ of the libraries produced higher CRs for the original samples, while $85.71 \%$ were more efficient in compressing the coefficients. The best CR obtained for the samples of this volume was $2.37: 1$ while the best ratio for the coefficients was $2.53: 1$. These results were obtained using the compressor blosc2-zstd, which combines the meta-compressor blosc2 with the compression library zstd.
Seismic data lossless compression with IWT approach

\begin{tabular}{|l|c|c|c|c|}
\hline \multirow{2}{*}{$\begin{array}{c}\text { Volume of } \\
\text { seismic data }\end{array}$} & \multicolumn{2}{|c|}{ Original samples } & \multicolumn{2}{c|}{$\begin{array}{c}\text { Wavelet } \\
\text { coefficients }\end{array}$} \\
\cline { 2 - 5 } & $\begin{array}{c}\text { \% of } \\
\text { better CR }\end{array}$ & $\begin{array}{c}\text { Best } \\
\text { CR }\end{array}$ & $\begin{array}{c}\text { \% of } \\
\text { better CR }\end{array}$ & $\begin{array}{c}\text { Best } \\
\text { CR }\end{array}$ \\
\hline F3Block $\left(^{*}\right)$ & 14.29 & $2.37: 1$ & 85.71 & $2.53: 1$ \\
\hline Waka3D $\left(^{* *}\right)$ & 21.21 & $1.72: 1$ & 78.79 & $1.85: 1$ \\
\hline Nornefield $\left(^{* * *}\right)$ & 3.85 & $1.67: 1$ & 96.15 & $1.81: 1$ \\
\hline
\end{tabular}

$\left(^{*}\right)$ F3Block: Open Repository, Netherlands Offshore

$\left({ }^{\star *}\right)$ Waka3D: Open Data, New Zealand

$\left({ }^{* * *}\right)$ Nornefield: Open Data, North Sea

\section{Conclusions}

This study shows that better CRs were obtained from the compression of wavelet coefficients instead of original samples, for the great majority of compressors (up to $96.15 \%$ of them). Among all analyzed compressors, blosc2-zstd has produced the best results in all cases: the best $C R$ was 2.53:1 and the average CR was 2.06:1. As a conclusion, using integer wavelet coefficients can be an interesting approach in the context of compressing massive data.

\section{Acknowledgments}

The authors would like to thank Petrobras for the financial support.

\section{References}

STIGANT, J. P.; ERGAS, R. A.; DONOHO, P. L.; MINCHELLA, A. S.; GALIBERT, P. Y. 1995. Field trial of seismic compression for real time transmission. In: Annual International Meeting, Oct. 1995, Soc. of Expl. Geophysicists, Exp. abstracts, 960-962.

KHKNE, F.; ABDUB-JAUWAD, S. 2000. Efficient seismic compression using the lifting scheme. In: Annual International Meeting. Aug. 2000, Soc. of Expl. Geophysicists, Exp. abstracts, 2052-2054.

GIURCANEANU, C.; TABUS, I.; ASTOLA, J. 1999. Integer wavelet transform based lossless audio compression, Proc. of the IEEE-EURASIP Workshop on Nonlinear Signal and Image Processing, Jun. 1999, 378382.

WANG, Xz.; TENG, Yt.; GAO, Mt. JIANG H. 2004. Seismic data compression based on integer wavelet transform. Acta Seismologica Sinica 17, 123-128. 